ISSN Print : $1411-951 \mathrm{X}$, ISSN Online : 20503-1716

Jurnal Ergonomi Indonesia

(The Indonesian Journal of Ergonomic)

Vol.3, No.2 : 1 Juli-Desember 2017

\title{
DESAIN KURSI ERGONOMIS IBU MENYUSUI MENURUNKAN KELUHAN OTOT DAN MENINGKATKAN MOTIVASI PEMBERIAN ASI EKSKLUSIF
}

\author{
I Made Anom Santiana ${ }^{1)}$, M. Yusuf ${ }^{2)}$, I Nyoman Sutapa ${ }^{3)}$ \\ ${ }^{1,2,3)}$ Staf Pengajar Politeknik Negeri Bali \\ Email : yusuf@pnb.ac.id
}

\begin{abstract}
Abstrak
Pemberian ASI eksklusif merupakan tanggung jawab ibu setelah melahirkan. Suatu kendala tersendiri bagi sang ibu jika selama proses menyusui jika tempat tidak sesuai dengan kondisi fisiologi tubuh. Sikap tubuh saat menyusui yang tidak fisiologis akan menyebabkan timbulnya keluhan bagi sang ibu. Keluhan yang muncul antara lain cepat lelah, sakit atau nyeri pada otot tertentu, dan kondisi kurang nyaman pada tubuh saat menyusui. Disamping itu, bagi ibu yang bekerja dan menyusui sepulang kerja akan mempengaruhi motivasinya dalam memberikan ASI eksklusif dalam enam bulan pertama sejak kelahiran bayi. Untuk mengatasi cepat lelah karena sikap dan posisi menyusui yang tidak fisiologis dilakukan penelitian dengan cara meyesuaikan sarana kerja/kursi termpat menyusui dengan antropometri sang ibu tersebut. Penelitian ini dilakukan menggunakan metode eksperimen dengan rancangan group within treatment (sama subyek). Tempat penelitian di Klinik Bersalin "CB" Kabupaten Badung, Bali. Jumlah sampel 12 ibu menyusui. . Keluhan otot skeletal ibu menyusui diprediksi dengan kuesioner Nordic Body Map, dan motivasi pemberian ASI eksklusif diukur dengan menggunakan kuesioner motivasi dengan 5 skala Liket. Data di analisis secara deskriptif dan inferensial. Untuk mengetahui perbedaan perlakuan, data dianalisis menggunakan uji t-pair. Hasil penelitian diperoleh bahwa ada perbedaan yang siginifikan pada keluhan otot skeletal dan motivasi pemberian ASI Eksklusif antara perlakuan 1 (menggunakan kursi lama) dengan perlakuan 2 (menggunakan kursi perbaikan). Terjadi penurunan keluhan otot skeletal sebesar 32,4\% dan peningkatan motivasi pemberian ASI Eksklusif sebesar 29,7\%. Disimpulkan bahwa desain kursi ergonomis ibu menyusui menurunkan keluhan otot dan meningkatkan motivasi pemberian asi eksklusif. Untuk itu disarankan kepada ibu menyusui agar menggunakan kursi ergonomis dalam meberikan ASI Eksklusif dan bagi pemerintah agar menyediakan kursi ergonomis pada fasilitas publik ruag ibu menyusui baik di terminal, bandara, maupun fasilitas publik yang lain.
\end{abstract}

Kata Kunci : Desain Kursi Ergonomis, keluhan otot skeletal, motivasi pemberian ASI Eksklusif

\section{Pendahuluan}

Proses menyusui termasuk dalam kategori proses kerja sang ibu dalam mengasuh anak. Pada proses kerja tidak lepas dari beban kerja, postur kerja, stress, dan motivasi. Proses menyusui ini merupana proses pemberian air susu ibu (ASI) pada bayi. Pada bayi umur $0-6$ bulan perlu diberikan ASI secara eksklusif.

Pemberian ASI sangat penting bagi tumbuh kembang yang optimal baik fisik maupun mental dan kecerdasan bayi. Oleh karena itu pemberian ASI perlu mendapat perhatian para ibu dan tenaga kesehatan agar proses menyusui dapat terlaksana dengan benar. Faktor 
ISSN Print : 1411 - 951 X, ISSN Online : 20503-1716

\section{Jurnal Ergonomi Indonesia}

\section{(The Indonesian Journal of Ergonomic)}

keberhasilan dalam menyusui adalah: (1)

komitmen ibu untuk menyusui, (2) pemberian ASI secara dini (early initiation) yang dimulai di tempat bersalin, (3) teknik dan posisi menyusui yang benar baik untuk ibu maupun bayi, (4) menyusui atas permintaan bayi (on demand), dan (5) diberikan secara eksklusif.

\section{Pemberian ASI eksklusif} merupakan tanggung jawab ibu setelah melahirkan. Pemberian ASI eksklusif ini paling tidak hingga bayi berumur 6 bulan. Selama pemberian ASI eksklusif, posisi ibu yang menyusui tergantung dari tempat dimana sang ibu melakukan pekerjaan menyusui tersebut, bisa di kursi, tempat tidur, sambil berdiri, dan sebagainya. Proses menyusui ini biasanya berlanjut hingga sang anak berumur 2 tahun. Beberapa kendala dalam pemberian ASI Eksklusif antara lain adalah (Mahfudin, 2012) : (a) ibu tidak percaya diri bahwa dirinya mampu menyusui dengan baik, hal ini disebabkan karena kurangnya pengetahuan ibu, (b) kurangnya dukungan tenaga kesehatan, fasilitas pelayanan kesehatan untuk mendukung keberhasilan ibu dalam menyusui bayinya.(c) faktor kesibukan kerja, (d) faktor fisik, karena anggapan akan merubah postur atau kecantikan tubuhnya, dan (e) faktor timbulnya kelelahan dalam menyusui. Faktor kelelahan bisa jadi kerena ketika menyusui posisi tubuh tidak alamiah, terjadi sikap tubuh yang membuat cepat terjainya keluhan otot. Hal ini terjadi karena tempat menyusui yang tidak sesuai dengan kondisi tubuh sang ibu, tidak sesuai dengan antropometrinya. Untuk itu salah satu upaya dalam meningkatkan motivasi ibu dalam memberikan ASI eksklusifnya adalah memberikan kenyamanan dalam menyusui. Kenyaman ini bisa diciptakan dengan mendesain kursi yang sesuai dengan antropometri sang ibu.

Akan menjadi kendala tersendiri bagi sang ibu jika selama proses
Vol.3, No.2 : 1 Juli-Desember 2017

menyusui, kursi yang ditempati tidak sesuai dengan kondisi fisiologi tubuh sang ibu. Sikap tubuh saat menyusui yang tidak fisiologis akan menyebabkan timbulnya keluhan bagi ibu menyusui. Keluhan yang muncul antara lain cepat lelah, keluhan sakit atau nyeri pada otot tertentu, dan kondisi kurang merasa nyaman pada sikap tubuh saat menyusui. Disamping itu, bagi ibu yang bekerja dan menyusui sepulang kerja akan mempengaruhi motivasinya dalam memberikan ASI eksklusif dalam enam bulan pertama sejak kelahiran bayi. Munculnya keluhan pada ibu menyusui biasanya sakit pada bagian otot tertentu pada tubuh setelah menyusui, seperti keluhan otot leher, pinggang, dan betis. Salah satu penyebab keluhan ibu adalah posisi/sikap dalam menyusui yang tidak alamiyah (karena tempat menyusui tidak sesuai dengan antropometri), sehingga munculnya kelelahan ini juga akan menurunkan motivasi sang ibu untuk memberikan ASI eksklusifnya.

Di samping itu, pemerintah sudah mengeluarkan kebijakan (UU No. 36/2009) yang menyatakan bahwa Pemerintah Daerah dan masyarakat harus menyediakan fasilitas khusus untuk ibu menyusui pada sarana umum (seperti bandara, stasiun, terminal, tempat kerja). Bahkan di negara maju, pada kendaraan bus umum sudah disediakan tempat untuk ibu menyusui. Di ruangan khusus untuk ibu menyusui tersebut biasanya juga diberikan tempat duduk untuk sang ibu menyusui bayinya. Akan tetapi jika tempat duduk ini tidak sesuai dengan antropometri sang ibu, maka akan timbul keluhan cepat lelah, sakit pada otot tertentu, dan ketidak nyamanan dalam pemakaian. Fasilitas kerja yang tidak ergonomis akan menyebabkan keluhan subjektif seperti keluhan pada sistem otot skeletal (Yusuf \& Santiana, 2014). Untuk mengatasi cepat lelah karena sikap dan posisi kerja yang tidak fisiologis dapat dilakukan dengan cara meyesuaikan antropometri manusia tersebut dengan bidang kerja pada saat mendesain tempat 
ISSN Print : 1411 - 951 X, ISSN Online : 20503-1716

\section{Jurnal Ergonomi Indonesia}

\section{(The Indonesian Journal of Ergonomic)}

kerja/kursi termpat menyusui (Sutajaya, 2003).

Oleh karena itu, perlu adanya desain kursi yang ergonomis untuk keperluan ibu menyusui dan sebagai kontribusi desain kursi difasilitas umum yang menyediakan ruang khusus bagi ibu menyusui sehingga keluhan otot skeletal pada sang ibu bisa terkurangi dan motivasi pemberian ASI eksklusif bisa meningkat.

\section{Materi dan Metode}

Penelitian ini menggunakan metode eksperimen dengan rancangan group within - treatment (sama subyek). Diantara kedua grup perlakuan ada waktu washing out. Tempat penelitian di Klinik Bersalin "CB", Kecamatan Kuta,
Vol.3, No.2 : 1 Juli-Desember 2017

KabupatenBadung, Bali. Jumlah sampel minimal dihitung dengan menggunakan rumus Colton (1974) sehingga diperoleh sampel 12 ibu menyusui. Keluhan otot skeletal ibu menyusui diprediksi dengan kuesioner Nordic Body Map, dan motivasi pemberian ASI eksklusif diukur dengan menggunakan kuesioner motivasi dengan 5 skala Likert. Data di analisis secara deskriptif dan inferensial. Untuk mengetahui perbedaan perlakuan, data keluhan otot dan motivasi dianalisis menggunakan uji t-pair.

\section{Hasil dan Pembahasan}

\subsection{Karakteristik Subjek Penelitian}

Jumlah sampel dalam penelitian ini adalah 12 orang ibu menyusui dengan karakteristik sebagai berikut.

Tabel 1 Karakteristik subjek penelitian

\begin{tabular}{clccc}
\hline No & \multicolumn{1}{c}{ Variabel } & Rerata & SB & \multicolumn{2}{c}{ Rentangan } \\
\hline 1 & Umur (th) & 29,14 & 2,57 & $24,5-36,5$ \\
2 & Berat badan $(\mathrm{kg})$ & 60,33 & 3,15 & $56,5-65,5$ \\
3 & Tinggi badan $(\mathrm{cm})$ & 158,67 & 2,44 & $154,5-169,5$ \\
4 & Indeks Massa Tubuh & 22,17 & 1,62 & $20,29-23,47$ \\
\hline
\end{tabular}

Berdasarkan Tabel 1 di atas, karakteristik subjek tergolong normal. Rentang umur ibu menyusui yang menjadi subjek penelitian ini berada pada rentang 24,5 hingga 36,5 tahun, termasuk usia produktif untuk melahirkan dan menyusui. indeks masa tubuh rata-rata adalah 22,17 yang menunjukkan bahwa kondisi fisik subjek berada pada kondisi yang baik dan normal. Empat kategori indeks masa tubuh (IMT) di Indonesia, yaitu kurus $(<17,0)$, normal $(18,0-25,0)$, gemuk $(25,1-27,0)$, dan obesitas (>30). Sedangkan beberapa hal lain yang bisa mempengaruhi IMT antara lain, usia, jenis kelamin, genetik serta aktivitas fisik (Depkes, 2001). Choobineh, et al (2007) menyatakan bahwa seseorang yang memiliki indeks masa tubuh abnormal berisiko mengalami keluhan nyeri dibagian tubuh seperti di daerah punggung bawah dua kali lebih tinggi dari pada orang dengan indeks masa tubuh normal.

\subsection{Kondisi Mikroklimat}

Kondisi mikroklimat yang diukur di lokasi penelitian selama penelitian berlangsung adalah suhu basah, suhu kering, kelembaban relatif, intensitas cahaya, dan kebisingan. Mikroklimat ini bisa mempengaruhi kondisi ibu ketika menyusui. Hasil pengukuran mikroklimat disajikan pada Tabel 2 berikut.

Tabel 2.Hasil Analisis Pengukuran Mikroklimat

\begin{tabular}{|c|c|c|c|c|c|c|c|}
\hline \multirow{2}{*}{ No } & \multirow{2}{*}{ Variabel } & \multicolumn{2}{|c|}{ Perlakuan 1} & \multicolumn{2}{|c|}{ Perlakuan 2} & \multirow[b]{2}{*}{$\mathrm{t}$} & \multirow[b]{2}{*}{ p } \\
\hline & & Rerata & SB & Rerata & SB & & \\
\hline 1 & Suhu basa & 23,17 & 1,25 & 22,96 & 1,21 & $-2,096$ & 0,132 \\
\hline 2 & Suhu kering (oC) & 28,14 & 1,22 & 27,97 & 1,34 & $-3,079$ & 0,224 \\
\hline 3 & Kelembaban relatif & 72,14 & 3,11 & 71,62 & 2,33 & 2,583 & 0,457 \\
\hline
\end{tabular}


ISSN Print : 1411 - 951 X, ISSN Online : 20503-1716

\section{Jurnal Ergonomi Indonesia}

(The Indonesian Journal of Ergonomic)

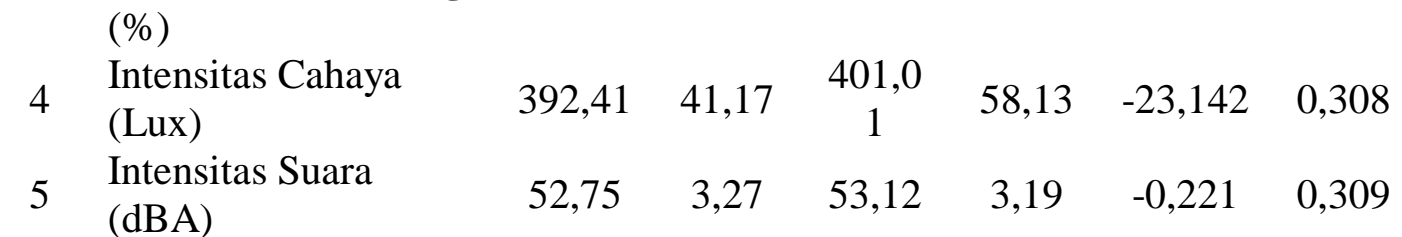

Keterangan : SB = Simpang Baku

Dari Tabel 2 menunjukkan bahwa kondisi lingkungan kerja baik pada perlakuan 1 (memakai kursi lama) maupun perlakuan 2 (memakai kursi baru) masih dalam batas-batas adaptasi untuk melakukan suatu aktivitas kerja dan tidak mempunyai perbedaan yang nyata antara keduanya $(\mathrm{p}>0,05)$. Oleh karena itu bisa dinyatakan bahwa kondisi mikroklimat memberikan efek yang sama pada kedua perlakuan. Kondisi mikroklimat seperti tertera pada Tabel 2 masih tergolong normal dan nyaman. Jika kondisi ruangan kurang nyaman akan memberikan beban tambahan pada subjek (ibu menyusui) (Kroemer dan Grandjean, 2009). Manuaba (1998) menyatakan bahwa nilai ambang batas dari suhu udara untuk pekerjaan dalam batas nyaman

adalah $33^{\circ} \mathrm{C}$ dan kelembaban relatif untuk orang Indonesia yang masih tergolong nyaman adalah antara $70 \%$ $80 \%$. Ambang batas kebisingan adalah 85 dB (BSN, 2004). Tempat menyusui yang nyaman akan menjadikan pekerjaan menyusui juga ikut nyaman.

\subsection{Keluhan Otot Skeletal}

Keluhan otot skeletal pada subjek penelitian diprediksi dengan kuesioner Nordic Body Map baik pada pelakuan 1 (menggunakan kursi lama) maupun pada pelakuan 2 (menggunakan kursi ergonomis). Uji perbedaan antara dua perlakukan tersebut menggunakan t-pair test. Hasil uji disajikan sebagaimana Tabel 3 berikut :

Tabel 3 Hasil Analisis Keluhan Otot

Skeletal

\begin{tabular}{ccccccc}
\hline \multirow{2}{*}{ variabel } & \multicolumn{2}{c}{ Perlakuan 1 } & \multicolumn{2}{c}{ Perlakuan 2 } & \multirow{2}{*}{$\mathrm{t}$} & $\mathrm{p}$ \\
\cline { 2 - 5 } & Rerata & SB & Rerata & SB & & \\
\hline $\begin{array}{c}\text { Keluhan Otot } \\
\text { Skeletal (pre) }\end{array}$ & 31,27 & 3,02 & 32,41 & 2,81 & 11,549 & 0,418 \\
\hline $\begin{array}{c}\text { Keluhan otot } \\
\text { skeletal (post) }\end{array}$ & 87,41 & 3,91 & 59,12 & 3,44 & 42,081 & 0,000 \\
\hline
\end{tabular}

Keterangan : $\mathrm{SB}=$

Simpang Baku

Terjadi perbedaan yang signifikan antara Perlakuan 1 (menggunakan kursi lama) dengan Perlakuan 2 (menggunakan kursi baru yang ergonomis) pada keluhan otot skeletal seperti terlihat pada Tabel 3 $(\mathrm{p}<0,05)$. Dilihat dari rerata keluhan otot skeletal, terjadi penurunan dari rerata 87,41 pada Perlakuan 1 menjadi 59,12 pada Perlakuan 2, atau menurun sebesar $32,4 \%$. Penurunan ini diprediksi terjadi karena bentuk kursi sudah sesuai dengan antropometri subjek (ibu menyusui) dan postur tubuhnya. Pheasant (2003) menerangkan bahwa sikap kerja duduk dalam waktu cukup lama dan

pembebanan otot statik akibat sikap kerja paksa menyebabkan terjadinya bendungan darah vena, penimbunan cairan dan varices vena pada kaki dan sering dirasakan sebagai bentuk kelelahan otot. Dengan menggunakan kursi ergonomis dengan bentuk yang sesuai dengan keperluan pengguna maka akan mengurangi kelelahan otot tersebut. Sikap kerja statis seperti duduk lama akan menimbulkan keluhan-keluhan, baik itu keluhan subyektif maupun keluhan obyektif yang terjadi pada otot skeletal (Kroemer and Grandjean, 2009), terlebih lagi kursi yang digunaka tidak sesuai 
ISSN Print : 1411 -951 X, ISSN Online : 20503-1716

\section{Jurnal Ergonomi Indonesia}

\section{(The Indonesian Journal of Ergonomic)}

Vol.3, No.2 : 1 Juli-Desember 2017

dengan antropometri dan keperluan pengguna. Maka akan dipastikan keluhan otot akan meningkat. Dengan menggunakan kursi ergonomis maka keluhan otot pada ibu menyusui ini akan berkurang. Penelitian yang dilakukan Putri dan Griadhi (2015) dan Yusuf et al. (2016), menyatakan bahwa perbaikan kondisi kerja yang ergonomis akan mampu menurunkan keluhan otot skeletal. Pada penelitian ini, keluhan otot skeletal diperoleh penurunan yang signifikan yaitu sebesar $32,4 \%$.

Tabel 4. Hasil Analisis Skor Motivasi

\begin{tabular}{ccccccc}
\hline \multirow{2}{*}{ variabel } & \multicolumn{2}{c}{ Perlakuan 1 } & \multicolumn{2}{c}{ Perlakuan 2 } & $\mathrm{t}$ & $\mathrm{p}$ \\
\cline { 2 - 7 } & Rerata & SB & Rerata & SB & & \\
\hline Motivasi & & & & & & \\
$\begin{array}{c}\text { Pemberian } \\
\text { ASI } \\
\text { Eksklusif }\end{array}$ & 40,72 & 3,42 & 52,81 & 4,36 & 47,519 & 0,000 \\
& & & & & & \\
\hline
\end{tabular}

Tabel 4 menunjukkan bahwa terjadi perbedaan yang signifikan ( $\mathrm{p}<$ $0,005)$ antara Pelakuan 1 dengan Perlakuan 2. Bisa dinyatakan bahwa penggunaan kursi ergonomis memberikan efek pada motivasi subjek yaitu ibu menyusui dalam memberikan ASI Eksklusifnya terhadap si bayi. Rerata skor motivasi pada perlakukan 1 adalah 40,72 sedangkan motivasi pada Perlakuan 2 adalah 52,81. Terjadi peningkatan sebesar $29,7 \%$. Peningkatan motivasi ini diprediksi karena adanya kenyamanan dalam penggunaan kursi ergonomis dan berkurangnya keluhan otot skeletal.

Pheasant (2003) menyebutkan bahwa aspek yang harus ditentukan dalam mendesain kursi adalah sesuai dengan antropometri dan keperluan pengguna. Hal ini akan menyebabkan kursi tersebut akan memberikan kenyamanan dan manfaat pemakain dari pengguna. Jika kursi yang digunakan lebih nyaman maka secara psikologis juga akan menambah motivasi pengguna untuk memakainya. Posisi duduk sang ibu dalam menyusui didukung dengan adanya sandaran pada punggung ibu. Hal ini akan memberikan kenyamanan ketika memberikan ASI Eksklusifnya pada sang bayi dalam waktu yang lama (Bahiyatun, 2009). Intervensi dengan penggunaan kursi ergonomis pada ibu menyusui ini termasuk intervensi yang holistik karena melihat dari berbagai aspek. Baik aspek task yaitu pemberian ASI Eksklusif pada bayi, aspek lingkungan yaitu kenyamanan ruangan, dan aspek pemanfaatan teknologi tepat guna. Pendekatak ini bisa disebut sebagai pendekatan yang holistik dalam menyelesaikan masalah (Manuaba, 2006). Hasil penelitian dari Sandra dan Ahmad (2010) menyebutkan bahwa perlu adanya solusi internal maupun eksternal untuk mensukseskan pemberian ASI Ekslusif bagi ibu menyusui. Kesuksesan ini harus didukung dorongan dari internal ibu menyusui (motivasi) maupun kebijakan harus dikeluarkan oleh pemerintah setempat.

\section{Kesimpulan dan Saran \\ 4.1 Kesimpulan}

Dari hasil analisis dan pembahasan penelitian di atas, dapat disimpulkan bahwa : 
ISSN Print : 1411 -951 X, ISSN Online : 20503-1716

Jurnal Ergonomi Indonesia

(The Indonesian Journal of Ergonomic)

a. Desain kursi ergonomis dapat menurunkan keluhan otot skeletal ibu menyusui.

b. Desain kursi ergonomis dapat meningkatkan motivasi pemberian asi eksklusif pada ibu menyusui.

\subsection{Saran}

Hasil penelitian menunjukkan bahwa penggunaan kursi ergonomis dapat membantu kesuksesan pemberian ASI Eksklusif bagi ibu menyusui, untuk itu disarankan kepada para ibu menyusui agar menggunakan kursi yang ergonomis ketika memberikan ASI kepada sang bayi. Terhadap pemerintah agar memberikan fasilitas kursi ergonomis pada ruangan khusus ibu menyusui pada fasilitas publik seperti di terminal, bandara, stasiun, dan fasilitas publik lainnya.

\section{Daftar Pustaka}

Bahiyatun. 2009. Asuhan Kebidanan Nifas Normal. Jakarta: EGC.

BSN. 2004. Nilai Ambang Batas iklim kerja (panas), kebisingan, getaran tangan-lengan dan radiasi sinar ultra ungu di tempat kerja. Badan Standarisasi Nasional. SNI 16-70632004.

Choobineh A, Tabatabaei, Sayed H, Mokhtarzadeh A, Salehi M. 2007. Musculoskeletal Problems among Workers of an Iranian Rubber Factory: Journal of Occupational Health 2007;49:48-423.

Colton, T. Sc.D. 1974. Statistic in Medicine. Boston : Litle Brown and Company.

Depkes RI. 2001. Karakteristik Berat Badan dengan IMT Indonesia. Jakarta:Depkes RI

Kroemer, K.H.E., and Grandjean, E. 2009. Fiting the Task to the Human,
Vol.3, No.2 : 1 Juli-Desember 2017

Textbook of Occupational Ergonomics, Fifth Edition. Taylor \& Francis Inc. London.

Mahfudin. 2012. Menyusui, Hak yang Menjadi Tantangan Bagi Ibu Bekerja.

Manuaba, A. 2006. Aplikasi Ergonomi dengan Pendekatan Holistik perlu, demi Hasil yang lebih lestari dan mampu bersaing. Juornal Sosial dan Humaniora 1(03):235-249

Manuaba, A.1998. Bunga Rampai Ergonomi vol.1. Program Studi Ergonomi-Fisiologi Kerja Universitas Udaayana Denpasar.

Pheasant, S. 2003. Body Space: Anthropometry, Ergonomic and Design of Work, $2^{\text {nd }}$ Edition. London: Tailor \& Francis.

Putri, P.D.W., Griadhi, I.P.A. 2015. Perbaikan Stasiun Kerja Menurunkan Aktivitas Listrik Otot Dan Keluhan Muskuloskeletal Pada Perajin Ukir Kayu Di Desa Batuan Gianyar Bali. E-jurnal Medika Udayana, Vol. 4, No.8.

Sandra F dan Ahmad S. 2010. Jurnal Makara, Kesehatan, Vol. 14, NO. 1, Juni 2010: 17-24.

Sutajaya, IM. 2003. Variasi Posisi dan Sikap Kerja Berpengaruh terhadap Keluhan Muskuloskeletal Pekerja di CV DS. Desa Mas Gianyar Bali. Majalah Kedokteran Udayana (Udayana Medical Journal) 34(120):90-93.

Yusuf, M. Adiputra, N. Sutjana, IDP. Tirtayasa, K. 2016. The Improvement of Work Posture Using RULA (Rapid Upper Limb Assessment) Analysis to Decrease Subjective Disorders of Strawberry Farmers in Bali. International Research Journal of Engineering, IT \& Scientific Research. Vol 2. NO 9. Sept 2016. p1-6. 
ISSN Print : 1411 - 951 X, ISSN Online : 20503-1716

Jurnal Ergonomi Indonesia

(The Indonesian Journal of Ergonomic)

Vol.3, No.2 : 1 Juli-Desember 2017

Yusuf, M. Santiana, M. 2014. Analisis Beban Kerja Mahasiswa Praktek di Bengkel Teknologi Mekanik Jurusan Teknik Mesin Politeknik Negeri Bali. Jurnal Ergonomi Indonesia (The Indonesian Journal of Ergonomic). Vol 7. No 2. Oktober 2014. p173-178. 